\title{
EFFECT OF WORD ORDER ON THE WRITINGS OF ESL LEARNERS - A CASE OF ARABIC LEARNERS
}

\author{
Dr Seetha Jayaraman \\ Asst.Professor \\ Dhofar University, \\ Sultanate of Oman \\ Email: seetha.jay@gmail.com
}

\begin{abstract}
One of the most frequently discussed problems in ESL teaching/learning situation is, applying the basic rules of grammar. The problem includes the use of appropriate verb tense/form, prepositions, correct use of gender/number of nouns and the like. Several studies have testified the existence of these problems with nonEnglish speaking ESL learners. The study investigates the common errors in word order made by a group of Arabic speaking undergraduate learners in terms of sentence construction, more specifically, with word order involving Noun-Adjective, Noun-Adverb and Auxiliary verb-Subject expressions. The errors consisting of these expressions in the writings of ESL classrooms are studied and the results show that the selection of appropriate adjective or adverb affects the word order in sentences and the comprehension of the message. These could arise partly due to overgeneralization of rules, incorrect learning of appropriate rules of grammar, and above all, Mother Tongue (MT) interference. The remedial measure is training the learners in using the rules discreetly and making the learners to distinguish between the structures in Arabic and those in English.
\end{abstract}

Key words: Arabic, Grammar, Mother Tongue, Second Language, Structure, Word Order.

\section{Introduction}

Every language has its rules of phonological, morphological and syntactic patterns and they are language specific. Mastery of these rules is clear evidence to the level of proficiency attained in the target language. English is one such language which, in terms of language typology, is an Subject-Verb-Object (SVO) language as opposed to Subject-ObjectVerb (SOV) languages like Hindi. Hence, word order in a sentence determines the sentence type and alters the semantic value of each word in the sentence.In other words, the position of constituents of the sentence determines the meaning imparted by the combination of words lexical items in the sentence.
For a learner of ESL, there are a few major differences between English and other languages. It is important to know and understand these differences to be able to apply the rules independently of the MT influence. Among the most common areas of difficulty for a non-English speaking learner are the use of various verb tenses, appropriate use of modals and auxiliary verbs, choosing the word order in a sentence, use of articles and appropriate vocabulary and so on. The present study focuses on word order in a sentence, with respect to use of adjectives with nouns and modal verbs with full verbs.

Arabic is a Semitic Language, widely used in the Middle Eastern countries, Asia and African countries, in different colloquial varieties and dialects. Its grammatical structure is very different from that of IndoEuropean languages. Therefore there are 
many areas of interference in their Second Language (L2) acquisition. The study takes into consideration these differences and focuses on the learners from the southern part of Oman, viz., Dhofar region.

\section{Objective of the study}

While learning English either as a Second Language (SL) or a Foreign Language (FL), a few common errorsare made by learners of other than English in selecting the sequence of words to convey the message in a sentence. The study focuses on Arabic speaking ESL learners who have limited exposure to English as a language of communication. They live and learn in a predominantly monolingual - monocultural situation.

The objective of the study is to identify the learning problems, concentrating on the use of Noun Phrase (NP) and Verb Phrase (VP), among the group of undergraduate students studied and to suggest remedial practices to improve their skills of sentence construction.

\section{Significance of the Study}

Meaning in English is conveyed by word order in English sentences. The learners face challenges in interpreting the meaning by modifying the word order in a sentence. This becomes even more challenging both for teaching and learning in the context of interference of contrasting grammatical rules from another entirely different language like Arabic. With the addition of adjuncts to the existing simple SubjectVerb-Object type of structure, most learners often confuse between the word order in Arabic with that in English.
The writings of non-English speaking learners like the subjects of the present study are largely affected by the errors of the type mentioned above. The results of the present study will identify the problems and help them to recognize these errors. The results of the study can be extended beyond the level of writing sentences to paragraphs and could prove to be useful in further developing writing skills.

\section{Results and discussions}

Swan and Smith (2001) report that "the basis of Arabic language is the threeconsonant root .............and all verb forms, nouns, adjectives, participles etc. are then formed by putting these three root consonants into fixed patterns, modified sometimes by simple prefixes and suffixes"(p.200). Following this pattern, the Arabic speaking ESL learners find it difficult and confusing to comprehend and employ the wide range of structural patterns which are not so regular in their use in English. Consequently, it is quite challenging for the learners of content words like nouns, verbs, adjectives with identical orthographic forms to put them in sentences.

In writing, precision and accuracy are two most important aspects that must be taken into consideration. In the view of Hedge (2003), the process of creating (a new piece of writing) is in itself messy. That is, the process of creating new writing in a language is more complicated compared to writing and creating something new in one's mother tongue. This implies further, that it is important to focus on the process of creating a writing right from the level of combining words to form phrases, clauses 
and sentences. The products of such focused work, (viz., larger creations of paragraphs or essays depending on the levels of learning in language) would ensure perfection and precision.

According to McGregor (2009), the sentence is the largest linguistic unit showing grammatical structure, the largest unit over which grammatical rules or patterns apply. Thus the notion of grammatical sentences is crucial in acquiring the correct composition of a meaningful sentence. It leads us to describe clauses as sequences of phrases as Noun Phrases (NP), Verb Phrase (VP), Prepositional Phrase (PP), Adjective Phrase (ADJ P) and so on, to refer to the constituents in a sentence.

In Arabic the sentences place the verb first, followed by the subject, more commonly observed in speech than in writing. This pattern is observed when they write in English. On an analogy with their MT, Arabic speaking learners produce sentences like,

(1) (a)*Told my father to my brother, to get anew car, whichcan be compared to,

(b) My father told my brother to get a new car.

Let us look at a few examples from the corpus.

(2) (a)*I a student.

(b) I am a student.

(3) (a)*My brother doctor.

(b) My brother is a doctor.

Interestingly, the auxiliary 'be' does not occur in the present tense forms in Arabic.
Therefore, the learner who is not a proficient speaker and has a very limited exposure to the spoken variety of English drops the 'be' verbs in all its forms in the present tense leading to sentences like sentences (2) and (3). This is a serious problem, in the sense that, the listener is not sure if the sentence is completed, or the speaker is going to add more information. There is either a communication breakdown or a miscommunication which can occur.

Mc Gregor (2009) believes that "Sentence structure in all human languages is complex, and .....varies considerably from language to language. However, in all languages two things are recurrent: the existence of units intermediate in size between words and sentences, and of grammatical relations between them. Differences in these units and relations permit us to distinguish different sentence types within and across languages."(p.103)In line with this view, the following examples from the sample writings illustrate that change in word order in a sentence can lead to ungrammatical or unacceptable sentences in English.

Fromkin et al (2007) describe Phrase Structure (PS rules as “...the"(p.135) allowable structures of the language, and these rules permit us to predict the structures that are possible to formulate each structure independently.

Let us consider the following example from English Noun Phrase:

\section{(7) the big beautiful garden}

The phrase can be represented by the rule, 
(9) (a)*You have finished your work $?$

[the] [big beautiful garden]

$$
\mathrm{NP} \longrightarrow[\text { Adj] [Adj] [N] }
$$

[big] [beautiful] [garden]

In a NP, there can be multiple adjectives like, "the kind old intelligent man", of which the simplest structure is as in (4) above.

We can see that in a NP there can be many adjectives but not many determiners. A determiner can be an article, a possessive adjective, a demonstrative adjective or a numeral. Furthermore, an adjective directly modifies the noun, while a determiner modifies the wholeAdj + NP, for example, "the strange little boy" but not "*the my young little boy". This shows the relationship which exists between the words within a given phrase.

Let us now look at an example of NP in Arabic.

(8) (a) * a pen blue (Arabic)

(b) a blue pen (English)

Irrespective of the Mother Tongue, most ESL learners face problems with interrogative and negative sentence formation, choosing the position of the Aux/Modal-Main verb in the correct order. It is either the same as the declarative sentence in the case of interrogative sentences like,

Table 1: Results of survey of problems of subjects in constructing correct sentences in English

\begin{tabular}{|l|l|c|c|}
\hline Sl.No. & \multicolumn{1}{|c|}{ Criteria } & \% of agreement & $\begin{array}{l}\% \text { of } \\
\text { disagreement }\end{array}$ \\
\hline 1 & Problem with choosing the right word & 67 & 33 \\
\hline 2 & There are no problems & 2 & 98 \\
\hline 3 & Problem with sentence grammar & 93 & 07 \\
\hline
\end{tabular}

In the case of negative sentences the choice of the past tense of the main verb as in the sentence,

(10) (a) *We didn't went to the shop yesterday. For,

(b) We didn't go to the shop

yesterday.

Another aspect that causes problems in the learners is the selection of a modal verb to convey the exact meaning intended. Here the syntactic structure of English sentences interferes with the choice of the right modal verb and understanding the meaning of the sentence as a whole. The meaning of compulsion, ability, permission, possibility, hypothesis conveyed through the use of modal verbs is often confused with those in Arabic, largely because of the word order of verbs.

The survey questionnaire was administered in order to check the level of comprehension of the writing problem and the extent of awareness in the learner. The results of the survey are shown in Table 1: 


\begin{tabular}{|l|l|c|c|}
\hline 4 & $\begin{array}{l}\text { Problem finding equivalent word in } \\
\text { English }\end{array}$ & 92 & 08 \\
\hline 5 & Problem with writing complete sentences & 5 & 95 \\
\hline 6 & Problem with writing correct word order & 86 & 14 \\
\hline
\end{tabular}

As we can observe, majority of the learners agree that they have problems of understanding the sentence grammar, choosing the correct right word, word order or an equivalent word to match their ideas for conveying meaning. This answers the research questions raised by the study. The results of the survey also confirm the factors which affectlearning sentence grammar viz., the sequencing ofwords in the construction of sentences in English.

There are several other factors which deter learning the rules of sentence grammar like word order in sentences:

(1) Lack of proper attention: This occurs normally due to the fact that the learner does not give importance to the structures in the new language, like English, where the rules of combination of words differ markedly from those of other languages.

(2) Language problem: Incomplete learning of the new language, and thinking in the Mother Tongue while using the new structures.

(3) Faulty method of instruction: Generally using the traditional grammar methods can cause problems in understanding and applying the rules of grammar to their writing.

(4) Spelling and Grammar: Incomplete learning of the spelling and grammar rules is largely responsible for learner problems leading to faulty spelling and incorrect sentence structures or patterns. This needs to be addressed if the learners need to produce a reasonably good level of writing beginning at word level.

\section{Conclusion}

Although there are several factors which contribute to the language output of the learner, one of the major factors lies in understanding and applying the concepts aptly. The learners of the study group can be divided into two broad categories. (a) those who understand the underlying principles operating in a language, but have difficulty in expressing themselves appropriately in suitable contexts and, (b) those who do not understand the basic concepts involved in the structure and functioning of language, and hence they cannot express themselves clearly and appropriately in suitable contexts. For both the categories of learners, the effective and convenient mode is to use the structures and patters of L1 where necessary, to strengthen their comprehension and elevate their level of proficiency in learning and using L2. The study observes that a comparative method of learning with the knowledge of the grammar and the usage of one's MT on the one hand and a bilingual method of instruction in the context of the present group of learners can prove to be 
efficacious to enable the learner to communicate confidently in the target language.

But, in the words of McGregor(2009), "...important to the success of secondlanguage learning are personality factors including motivation, aptitude, attitude and empathy".(p.221). Using these factors in ESL teaching/learning, can produce the results envisaged.

\section{References}

[1] Benati, Assendro G. (2013). Issues in Second Language Teaching.Sheffield: Equinox Publishing Ltd.

[2] Fromkin, V.et al (2007).An Introduction to Language. ( $\left.8^{\text {th }} \mathrm{ed}\right)$.Boston: Thomson.

[3] Hedge, Tricia.(2003). Teaching and Learning in the Language Classroom. OUP.

[4] McGregor, W.B.(2009). Linguistics- An Introduction. London:Continuum International Publishing Group.

[5] Nunan,D.(1999).Second Language Learning and Teaching. Boston: Heinle and Heinle Publishers.

[6] Swan M. \& Smith, B. (2001)

(Ed).Learner English A teacher's guide to interference and other problems Cambridge Handbooks for Language Teachers, ( $2^{\text {nd }}$ ed.).Cambridge: Cambridge University Press.

[7] Ur, Penny. (2005) A course in languageteaching: practice and theory, Cambridge: Cambridge University Press (pp.276).

[8] Yule, George. (2014) The Study of EnglishLanguage ( $5^{\text {th }}$ Ed).New York: Oxford University Press. 